STUDI

FRANCESI

\section{Studi Francesi}

Rivista quadrimestrale fondata da Franco Simone

Varia

\title{
Aa. Vv., Il poeta e il suo pubblico. Lettura e commento dei testi lirici nel Cinquecento, Convegno internazionale di studi a cura di Massimo Danzi e Roberto Leporatti
}

\section{Dario Cecchetti}

\section{OpenEdition}

\section{Journals}

Edizione digitale

URL: http://journals.openedition.org/studifrancesi/2103

DOI: 10.4000/studifrancesi.2103

ISSN: 2421-5856

Editore

Rosenberg \& Sellier

\section{Edizione cartacea}

Data di pubblicazione: 1 aprile 2014

Paginazione: 128

ISSN: 0039-2944

\section{Notizia bibliografica digitale}

Dario Cecchetti, «Aa. Vv., Il poeta e il suo pubblico. Lettura e commento dei testi lirici nel Cinquecento, Convegno internazionale di studi a cura di Massimo Danzi e Roberto Leporatti », Studi Francesi [Online], 172 (LVIII | I) | 2014, online dal 01 avril 2014, consultato il 18 septembre 2020. URL : http:// journals.openedition.org/studifrancesi/2103; DOI : https://doi.org/10.4000/studifrancesi.2103

Questo documento è stato generato automaticamente il 18 settembre 2020.

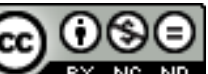

Studi Francesi è distribuita con Licenza Creative Commons Attribuzione - Non commerciale - Non opere derivate 4.0 Internazionale. 
Aa. Vv., Il poeta e il suo pubblico. Lettura e commento dei testi lirici nel Cinquecento, Convegno internazionale di studi a cura di Massimo Danzi e Roberto Leporatti Dario Cecchetti 


\section{NOTIZIA}

AA. VV., Il poeta e il suo pubblico. Lettura e commento dei testi lirici nel Cinquecento, «Convegno internazionale di studi: Ginevra, 15-17 maggio 2008», a cura di Massimo DANZI e Roberto LEPORATTI, Genève, Droz, 2012 («Travaux d'Humanisme et Renaissance», n. CDLXXXII / «Textes et Travaux de la Fondation Barbier-Mueller pour l'Étude de la poésie italienne de la Renaissance», n. 2), pp. 560.

1 Il convegno di cui si pubblicano qui gli Atti è nel suo complesso un convegno di italianistica, ma ha dei risvolti, sul piano metodologico, che interessano un area culturale ben più ampia di quella italiana, per esempio quella francese. Per questo ne facciamo breve segnalazione in questa sede. Il presente convegno «restringe per un verso il campo di investigazione al canone lirico del Cinquecento e, per un altro, lo allarga alle varie modalità che quel secolo sperimenta nella lettura e nel commento». Gli Atti offrono un contributo alla descrizione della tipologia del commento, o meglio di quelle forme di commento ristrette all'ambito lirico. Tipologia che ha per certo ampia corrispondenza nel proliferare di commenti coevi nella Francia rinascimentale (basti pensare ad affinità di 'generi' e di esperienze all'interno del petrarchismo sia italiano che francese). 